\title{
Agôn
}

Revue des arts de la scène

Critiques | Saison 2011-2012

\section{Dis-moi qui tu hais, je te dirai qui tu es}

Invasion ! de Jonas Hassen Khemiri, mis en scène par Antù Romero Nunes

\section{Marion Siéfert}

\section{(2) OpenEdition}

Journals

Édition électronique

URL : http://journals.openedition.org/agon/2237

DOI : $10.4000 /$ agon.2237

ISSN : 1961-8581

\section{Éditeur}

Association Agôn

\section{Référence électronique}

Marion Siéfert, «Dis-moi qui tu hais, je te dirai qui tu es », Agôn [En ligne], Critiques, mis en ligne le 18 mai 2012, consulté le 23 septembre 2020. URL : http://journals.openedition.org/agon/2237 ; DOI : https://doi.org/10.4000/agon.2237

Ce document a été généré automatiquement le 23 septembre 2020

Association Agôn et les auteurs des articles 


\title{
Dis-moi qui tu hais, je te dirai qui tu
}

\section{es}

\author{
Invasion! de Jonas Hassen Khemiri, mis en scène par Antù Romero
}

Nunes

\section{Marion Siéfert}

\section{RÉFÉRENCE}

Présenté dans le cadre du Festival Impatience à l'Odéon - Ateliers Berthier, du 9 au 10 mai 2012.

1 À l'heure de l'obsession identitaire, Invasion! de Jonas Hassen Khemiri, mis en scène par le jeune et talentueux Antù Romero Nunes, attaque une société qui, derrière chaque individu, cherche une appartenance, et derrière chaque nom, veut plaquer une identité aussi solide et morte qu'une image. Terrain de jeu et de mensonges, le plateau de théâtre devient le lieu de la subversion des certitudes, lorsque l'illusion prime sur la violence du démasquage.

2 Il y a des spectacles qui donnent envie de croire au théâtre, comme on peut croire à la démocratie telle que la pense Jean-Jacques Rousseau, à la pertinence d'un dispositif qui nous permet de mieux penser la complexité des rapports sociaux. Invasion ! est de ceuxlà. Porté par quatre acteurs endossant une bonne vingtaine de rôles au cours de la pièce, il se sert avec astuce et intelligence des armes de la représentation théâtrale, jouant sur la fiction de la scène, afin de révéler la brutalité du rôle, de l'identité unique, que la société occidentale a tendance à plaquer sur les individus.

3 C'est sur un nom que se lance le spectacle : «Abulkasem », le personnage d'un conte, rapidement interrompu par une blague hilarante des acteurs. Puis ce nom devient un simple mot, pris pour ce qu'il est : un signifiant qui peut vouloir dire tout et n'importe quoi, le nouveau mot fétiche choisi par une bande de lascars pour exprimer leur rapport au monde d'une façon codée. Cette expression devient alors le signe de l'identité d'une communauté, revendiquant ainsi sa différence : «Et puis Abulkasem, 
c'est devenu genre, un mot, tout seul. Au début ça voulait dire quelque chose de nase, faible, qui tenait pas la route, vague... [...] Puis, au bout de quelques semaines, je ne sais pas exactement comment... le mot a changé de sens, ça commençait à vouloir dire quelque chose genre, qui pète grave, qui déchire, à bloc... [...] ». Mais le jeu de langage de cette micro-communauté est vite interrompu par les quatre acteurs, prenant le mot au sérieux. Qui est Abulkasem ? Où se cache-t-il ? Et surtout : est-il dangereux ?

Commence alors une chasse à l'homme, traquant coûte que coûte une identité aux contours flous et fantasmés. Incarné tour à tour par les comédiens, Abulkasem prend des identités variées : prince de conte des Mille et une nuits, jeune turc voulant séduire une étudiante, metteure en scène turque aux idées géniales, immigré sans-papier devenu ennemi national, allégorie de la souffrance, etc. On l'aura compris : cette valse des rôles est bien une charge contre l'identité telle que la société la construit, à la fois appartenance à une classe, à une catégorie d'individus, mais aussi croyance en une stabilité des êtres, en une organisation bipolaire du monde (occidental vs islamique). La pièce démasque alors avec férocité le raisonnement tautologique d'une construction identitaire: angoissée face à un nom inconnu, pire, aux consonances étrangères, assignable à aucune identité précise, la société occidentale ne peut faire autrement que chercher, coûte que coûte, à remplir ce nom sans contenu.

On assiste aux inquisitions modernes : des étudiants en théâtre - satire féroce d'une ignorance bien pensante - mettent leur camarade de classe kurde à la question, l'interrogeant sur ses origines, et enfilent les poncifs comme des perles, tandis qu'elle essaie d'éluder en vain la conversation par un silence ostensible; un immigré sanspapier est transformé par le discours de son interprète en terroriste, tandis qu'il déclame sa passion pour le groupe Abba ; les acteurs de la pièce demandent enfin à leur partenaire d'exprimer son "vrai moi », de montrer qui «il est vraiment», en un mot: d'arrêter de jouer. Face aux grimaces terriblement gênées de ce comédien privé de ses armes, cherchant dans des plaisanteries une parade à son malaise, on comprend alors la brutalité de cette obsession identitaire, qui croit en une vérité lisse, sérieuse, univoque, tandis que les protestations timides du comédien révèlent en creux, ce qu'est son identité : une action, un bon jeu d'acteur, une intelligence face à une situation donnée.

Contre une société qui ne supporte pas le mensonge et le soupçonne partout, la mise en scène d'Antù Romero Nunes réalise des tours de théâtre, fait valser rôles et identités et répond ainsi à cette obsession de figer les êtres en les classant dans des catégories. Son originalité est de rompre l'illusion comique, non pas pour révéler la véritable personne qui se cacherait derrière le masque de l'acteur, mais pour nous dire la violence du démasquage, la brutalité à vouloir figer une action, un récit, un jeu, dans l'immobilité d'une essence.

\section{INDEX}

Mots-clés : Khemiri (Jonas Hassen), Nunes (Romero Antù), Invasion, Odéon Théâtre de l'Europe 